\title{
Fuel selection by the kidney: adaptation to starvation
}

\author{
BY GABRIEL BAVEREL, BERNARD FERRIER \\ AND MIREILLE MARTIN \\ Laboratoire de Physiopathologie Métabolique et Rénale, Faculté de Médecine Alexis Carrel, \\ 12 rue Guillaume Paradin, 69372 Lyon Cedex 08, France
}

\section{Sélection de substrats énergétiques par le rein}

\begin{abstract}
RÉSUMÉ
Pour couvrir ses besoins énergétiques in vivo, le rein, qui a un apport sanguin et une consommation d' $\mathrm{O}_{2}$ importants, est capable de métaboliser une grande variété de substrats. Le néphron, qui est l'unité fonctionnelle du rein, est fait de segments successifs morphologiquement, fonctionnellement et métaboliquement différents. Les déterminants de la sélection des substrats énergétiques par un segment spécifique de néphron qui agissent ensemble sont (1) l'existence et les propriétés cinétiques des transporteurs de substrats à travers les membranes apicale ou basolatérale des cellules rénales, (2) l'existence et l'activité de voies métaboliques pour l'apport et la consommation d'énergie, (3) l'environnement local et (4) l'état métabolique et hormonal de l'organisme qui détermine non seulement la disponibilité et la compétition des substrats au niveau du rein, mais aussi les modifications adaptatives des transporteurs, des voies métaboliques et de leurs régulations dans le rein. Les principales sources potentielles d'énergie pour le rein sont le glucose, le lactate, les acides gras, les corps cétoniques, le citrate, le glycérol et la glutamine. La manière dont ces substrats sont sélectionnés dans le rein intact et dans différents segments de néphron est illustrée dans des conditions métaboliques différentes (à l'état nourri, pendant le jeûne et pendant l'acidose métabolique). Ces exemples montrent que (1) l'apport de substrats au rein in vivo dépasse largement ses besoins énergétiques, (2) chaque segment de néphron a ses caractéristiques propres pour la sélection de substrats et (3) on sait souvent imparfaitement ou pas du tout où est le site précis de l'utilisation des substrats in vivo, dans quelle mesure chacun des substrats captés est utilisé comme source d'énergie, et quelle est la base moléculaire des modifications adaptatives de l'utilisation des substrats par le rein.
\end{abstract}

Although the kidney tissue represents less than $0.5 \%$ of the body weight, it receives $20-25 \%$ of the cardiac output and accounts for about $10 \%$ of whole-body $\mathrm{O}_{2}$ consumption, representing intense synthetic activity supplying the ATP needed to reclaim most of the solutes filtered through glomerular membranes (Cohen \& Barac-Nieto, 1973). Since energy reserves, in the form of glycogen and phosphocreatine (Needleman et al. 1968; Bastin et al. 1987) or neutral lipids (Hohenegger \& Schuh, 1980; Tannenbaum et al. 1993), are very low the kidney must extract and degrade circulating substrates to supply its energetic needs. The aim of the present review is to provide a general picture of the 
nature and amounts of substrates taken up by the rat kidney and of the cellular and molecular mechanisms whereby the kidney selects its fuels in the fed and fasted states.

\section{SUBSTRATE UTILIZATION AT THE WHOLE-ORGAN LEVEL}

Identification and quantification of the major substrates taken up by the kidney can be achieved by determining renal clearances, blood flow and arterio-venous concentration differences. Using microanalytical methods based on enzymic cycling, Elhamri et al. (1993) measured simultaneously the renal uptake or release of twelve different circulating metabolites in both fed and $72 \mathrm{~h}$-starved rats (Table 1). In the fed state, lactate and possibly glucose were the main substrates taken up by the rat kidney; other substrates taken up to a smaller but significant extent included fatty acids, ketone bodies, citrate, glutamine and glycerol. Glutamate, $\alpha$-ketoglutarate and pyruvate, taken up in only small amounts, could not make a significant contribution to the renal energy provision (Elhamri et al. 1993). Other studies have shown that lactate (Squires et al. 1976; Goldstein, 1987), ketone bodies and citrate (Goldstein, 1987), but not glucose or glutamine (Squires et al. 1976; Hohenegger \& Schuh, 1980; Goldstein, 1987), are utilized by the kidney of fed rats. In contrast with the results of Elhamri et al. (1993), a net release of glucose (Churchill et al. 1973; Kida et al. 1978), total free fatty acids, free glycerol and triacylglycerols (Hohenegger \& Schuh, 1980) was observed in the renal vein of fed rats.

Table 1. Concentrations of renal substrates in arterial blood, their uptake by the kidney and the oxygen equivalents of uptakes in fed and $72 \mathrm{~h}$-starved rats (From data of Elhamri et al. 1993)

(The values are means. The sum of $\mathrm{O}_{2}$ equivalents of the substrates taken up was calculated without taking into account the uptake of glucose)

\begin{tabular}{|c|c|c|c|c|c|c|}
\hline \multirow[b]{2}{*}{ Substrate } & \multicolumn{3}{|c|}{ Fed rats } & \multicolumn{3}{|c|}{ Starved rats } \\
\hline & $\begin{array}{c}\text { Blood } \\
\text { concentration } \\
(\mathrm{mM})\end{array}$ & Uptaket & $\begin{array}{c}\mathrm{O}_{2} \\
\text { equivalent } \dagger\end{array}$ & $\begin{array}{c}\text { Blood } \\
\text { concentration } \\
(\mathrm{mM})\end{array}$ & Uptake $\dagger$ & $\begin{array}{c}\mathrm{O}_{2} \\
\text { equivalent } \dagger\end{array}$ \\
\hline Citrate & $0 \cdot 17$ & $1 \cdot 5$ & 6.8 & $0 \cdot 14^{*}$ & $1 \cdot 3$ & 5.9 \\
\hline Lactate & 1.23 & $6 \cdot 1$ & $18 \cdot 3$ & $0.57^{*}$ & $2 \cdot 2^{*}$ & $6 \cdot 6$ \\
\hline Glycerol & $0 \cdot 10$ & $1 \cdot 1$ & $3 \cdot 9$ & $0 \cdot 11$ & $1.8^{*}$ & $6 \cdot 3$ \\
\hline $\mathrm{AcAc}$ & $0 \cdot 36$ & 1.9 & $7 \cdot 6$ & $1 \cdot 05^{*}$ & $5 \cdot 5^{*}$ & $22 \cdot 0$ \\
\hline$\beta-\mathrm{OH}-\mathrm{B}$ & $0 \cdot 18$ & 0.6 & 2.7 & $1 \cdot 81^{*}$ & $4 \cdot 8^{*}$ & $21 \cdot 6$ \\
\hline Glutamate & 0.13 & 0.2 & $0 \cdot 9$ & $0 \cdot 14$ & 0.2 & 0.9 \\
\hline Glutamine & 0.45 & 0.9 & $4 \cdot 1$ & $0 \cdot 44$ & $2 \cdot 3^{*}$ & $10 \cdot 4$ \\
\hline FFA & 0.91 & 0.5 & $11 \cdot 5$ & $1 \cdot 57^{*}$ & $2 \cdot 8^{*}$ & $64 \cdot 4$ \\
\hline Glucose & $7 \cdot 34$ & $6 \cdot 6$ & $39 \cdot 6$ & $4 \cdot 39^{*}$ & $4 \cdot 0$ & $24 \cdot 0$ \\
\hline Sum & - & - & $55 \cdot 8$ & - & - & $138 \cdot 1$ \\
\hline
\end{tabular}

FFA, plasma free fatty acids; AcAc and $\beta-\mathrm{OH}-\mathrm{B}$, acetoacetate and $\beta$-hydroxybutyrate respectively.

* Mean values for starved rats were significantly different from those for fed rats $(P<0 \cdot 05)$.

$\dagger$ Values of uptake and $\mathrm{O}_{2}$ equivalents are expressed in $\mu \mathrm{mol} / \mathrm{kg}$ body weight per min for one kidney. $\mathrm{O}_{2}$ equivalents: 3 for lactate; 3.5 for glycerol, 4.0 for acetoacetate, 4.5 for glutamine, glutamate, $\beta$-hydroxybutyrate and citrate, 6 for glucose and 23 for FFA. 
Elhamri et al. (1993) recognized that, given the small percentage of circulating glucose extracted by the kidney, their data on renal handling of this substance, like those of other authors, are not reliable. Thus, depending on whether the glucose uptake is included in the calculations (Table 1), the sum of the oxygen equivalents required for complete oxidation of the substrates taken up by the kidney of fed rats exceeds, or is in agreement with, the published values (Weinstein \& Szyjewick, 1976) of renal $\mathrm{O}_{2}$ consumption in the rat in vivo. Neglecting the contribution of glucose and assuming complete oxidation of all the other substrates taken up, oxidation of lactate, fatty acids, ketone bodies and citrate would account for 33, 21, 19 and $12 \%$ of total calculated renal $\mathrm{O}_{2}$ consumption (see Table 1). Since the synthesis of fatty acids in the kidney is very low (Hohenegger \& Schuh, 1980), the only possible fate of the ketone bodies metabolized by the kidney is complete oxidation. Therefore, even in the fed state, ketone bodies and particularly acetoacetate, appear to contribute substantially to the renal energy provision.

As shown in Table 1, Elhamri et al. (1993) found that starvation for $72 \mathrm{~h}$ led to a large increase in blood ketone body and fatty acid concentrations and to a large fall in blood lactate and glucose concentrations; the circulating concentrations of other potential renal substrates, except citrate which fell slightly, did not significantly change. Starvation caused a large stimulation of the renal uptake of ketone bodies and fatty acids and, to a lesser extent, of glutamine and glycerol and, by contrast, lactate uptake was diminished whereas that of glucose did not change significantly. The changes in the renal uptake of ketone bodies, fatty acids and lactate were proportional to the changes in the arterial supply of these compounds. The renal blood flow, glomerular filtration rate and urine volume were not altered by starvation. Again, neglecting the contribution of glucose, the complete oxidation of all other substrates taken up by the kidney would lead to a considerable increase in renal $\mathrm{O}_{2}$ consumption (Table 1). Unfortunately, the concomitant $\mathrm{O}_{2}$ consumption was not measured in these experiments. Unless there was some uncoupling effect of oxidative phosphorylation caused for example by the increased supply of fatty acids, such an increase in renal $\mathrm{O}_{2}$ consumption is unlikely because the renal reabsorption of $\mathrm{Na}$, the main process responsible for renal $\mathrm{O}_{2}$ consumption (Cohen \& Barac-Nieto, 1973), remained unchanged in the $72 \mathrm{~h}$-starved rats when compared with that in fed rats $(505 \nu .486 \mu \mathrm{mol} / \mathrm{kg}$ per min for one kidney respectively). This means that a large proportion of the substrates taken up has probably been converted into compounds not measured in this study that were either stored in situ or exported via the renal vein. A substantial uptake of free fatty acids and glycerol and their probable incorporation into triacylglycerols is suggested by a significant increase in the concentration of triacylglycerols in the renal cortex of the rat after a $24 \mathrm{~h}$ fast (Hohenegger \& Schuh, 1980; Wirthensohn et al. 1980); in agreement with this view also is the demonstration by the same authors that the net renal release of glycerol and total fatty acids found in fed rats was converted into a net uptake in $24 \mathrm{~h}$-starved rats. Thus, the latter observations together with the results obtained by Elhamri et al. (1993; see also Table 1) lead to the unavoidable conclusion that ketone bodies are the preferred fuels of renal respiration during starvation. However, this conclusion does not rule out the possibility that the other substrates taken up (free fatty acids, citrate, lactate, glycerol, glutamine and perhaps glucose) also make some contribution to the renal energy supply.

It should be emphasized that the conclusions drawn from renal substrate balance experiments, which yield useful information about the relative importance of potential fuels of the kidney in vivo, suffer from a number of important limitations. Because of the 
high renal blood flow and small arterio-venous concentration differences, large errors are inherent in this experimental approach, particularly for substances such as glucose circulating at high concentrations. The rates of substrate uptake or metabolite release measured are only net rates and do not take into account the possibility that synthesis and degradation of a given substrate occur simultaneously. Indeed, it is well established that whole rat kidney has the capacity to utilize glucose via glycolysis (Hems \& Gaja, 1972; Cohen et al. 1977; Anaizi \& Cohen, 1991) and synthesize glucose via gluconeogenesis (Nishiitsuji et al. 1967; Bowman, 1970; Hems \& Gaja, 1972). Similarly, whole rat kidney can form lactate by glycolysis under aerobic or anaerobic conditions (Hems \& Gaja, 1972; Bartlett et al. 1984) and utilize lactate as a substrate (Nishiitsutji et al. 1967; Bowman, 1970; Cohen et al. 1977; Bartlett et al. 1984). Also, rat kidney (Damian \& Pitts, 1970; Hems, 1972) contains significant activities of both glutamine synthetase (Richterich \& Goldstein, 1958; Lemieux et al. 1976; Burch et al. 1978a), the enzyme responsible for glutamine synthesis, and phosphate-activated glutaminase (Richterich \& Goldstein, 1958; Curthoys \& Lowry, 1973), which initiates the degradation of glutamine. Since the renal activity of $\beta$-hydroxybutyrate dehydrogenase is high (Robinson \& Williamson, 1980), acetoacetate and $\beta$-hydroxybutyrate are readily interconverted in whole rat kidney (Goldstein et al. 1982). Similarly, glycerol and free fatty acids can be incorporated into and released from triacylglycerols by rat kidney in vivo (Hohenegger $\&$ Schuh, 1980). Citrate may also be degraded and synthesized by rat kidney (Simpson, 1983). Therefore, if all or some of these opposing metabolic processes occur concurrently in vivo, the real contribution of each potential fuel to the provision of energy to the kidney is difficult to establish on the basis of renal balance studies performed in vivo. Furthermore, these experiments do not allow identification of the precise nephron segment where substrate metabolism occurs, nor the extent of substrate oxidation and interaction or the cellular mechanisms of adaptation to changing situations. Therefore, complementary information is needed at the cellular and subcellular levels.

\section{SUBSTRATE UTILIZATION AND OXIDATION AT THE NEPHRON SEGMENT LEVEL}

\section{Metabolic heterogeneity of the rat kidney}

Excellent reviews are available on the metabolic heterogeneity of the kidney (Guder \& Schmidt, 1976; Ross \& Guder, 1982; Guder \& Ross, 1984; Kurokawa et al. 1985; Guder et al. 1986; Wirthensohn \& Guder, 1986; Guder \& Morel, 1992). In brief, the kidney comprises the cortex, which represents about $70 \%$ of the organ weight, and the medulla which is divided into the outer and inner medulla (Pfaller \& Rittinger, 1980). About $90 \%$ of the renal blood flow is distributed to the cortex, allowing a large $\mathrm{O}_{2}$ supply and a high $\mathrm{pO}_{2}$ in this renal zone (Leichtweiss et al. 1969). The renal blood flow and the $\mathrm{O}_{2}$ supply to the outer medulla may become rapidly limiting and, therefore, the metabolism of this renal zone may shift from aerobic to anaerobic. The paucity of mitochondria (Guder \& Morel, 1992) and the low $\mathrm{pO}_{2}$ (Leichtweiss et al. 1969) of the inner medulla suggest that the nephron segments contained in this part of the kidney rely on anaerobic glycolysis to supply their energetic needs. The osmolality, progressively increasing in the medulla along the cortico-medullary axis, is an additional factor liable to influence the renal medullary energy metabolism as demonstrated in microdissected rat medullary collecting tubules and thick ascending limbs of Henle (Hus-Citharel \& Morel, 1986). Fig. 1 shows 


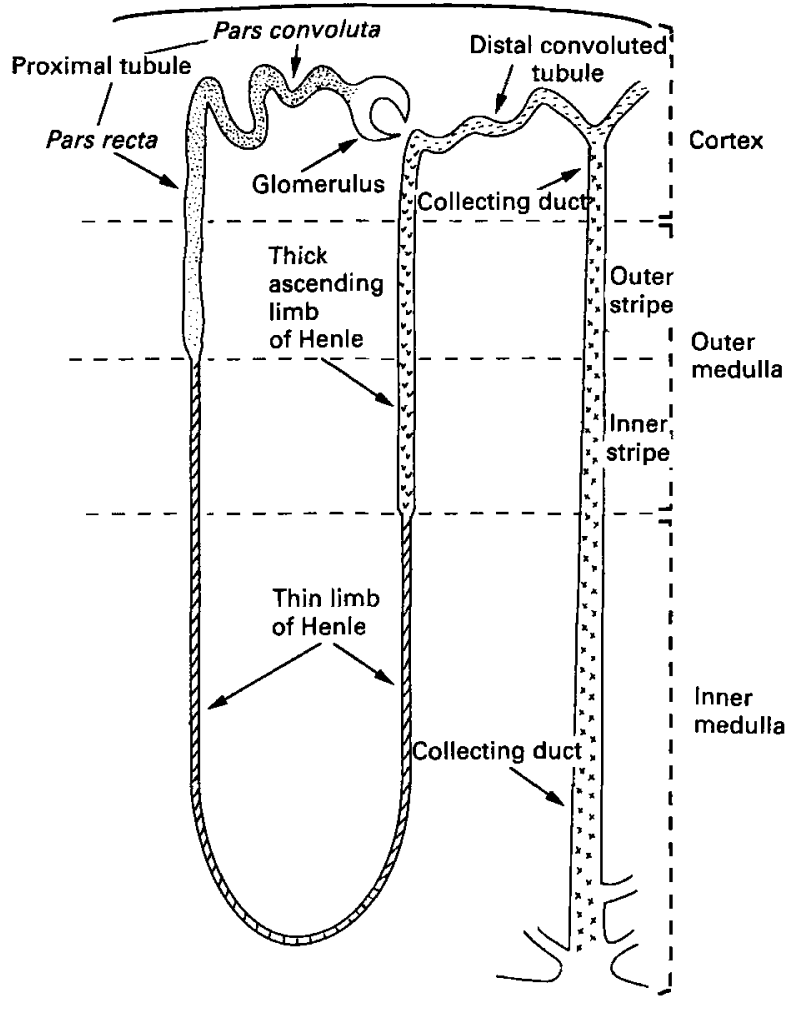

Fig. 1. Interrelationships between the various segments of the nephron and the different renal zones.

schematically the interrelationships between the various segments of the nephron, the functional unit of the kidney, and the different renal zones (for details, see Kriz \& Bankir, 1988).

The distribution of the activities of oxidative enzymes parallels the content of mitochondria and the activity of $\mathrm{Na}^{+}, \mathrm{K}^{+}$-ATPase (EC 3.6.1.37), considered to be the main enzyme responsible for the reabsorptive transport of $\mathrm{Na}^{+}$across the basolateral membrane of renal cells (Guder \& Morel, 1992). For example, the highest activities of enzymes of the citric acid cycle, of 3-oxoacid-CoA transferase (EC 2.8.3.5) and of $\beta$-hydroxyacyl-CoA dehydrogenase ( $E C$ 1.1.1.35; Le Hir \& Dubach, 1982a,b; Burch et al. 1984) are found in the thick ascending limb of Henle, the distal convoluted tubule and the proximal tubule whereas lower activities of these enzymes are found in the glomerulus, collecting duct and deep medullary segments of the nephron. Key enzymes of glycolysis (hexokinase (EC 2.7.9.1), phosphofructokinase 1 (EC 2.7.1.11) and pyruvate kinase (EC 2.7.1.40)) are most active in all distal nephron segments (Burch et al. 1974; Schmidt et al. 1975; Schmidt \& Dubach, 1976) and much less active in the proximal tubule (pars convoluta and pars recta) which is the only nephron segment containing significant activities of glycerol kinase (EC 2.7.1.30; Burch et al. 1982) and of the key enzymes (pyruvate carboxylase ( $E C$ 6.4.1.1), phosphoenolpyruvate carboxykinase (EC 4.1.1.49), fructose bisphosphatase (EC 3.1.3.11) and glucose-6- 
phosphatase (EC 3.1.3.9)) of gluconeogenesis (Burch et al. 1978b; Salto et al. 1991). Significant activity of lactate dehydrogenase ( $E C$ 1.1.1.27), an enzyme common to glycolysis and gluconeogenesis, is present along the entire length of the nephron (Burch et al. 1974): The activity of phosphate-activated glutaminase (EC 3.5.1.2; Curthoys \& Lowry, 1973; Wright \& Knepper, 1990b) is present in all nephron segments of the rat, whereas that of glutamine synthetase $(E C$ 6.3.1.2) is restricted to the straight portion (the pars recta) of the proximal tubule (Burch et al. 1978a).

Incubation of microdissected rat nephron segments with equimolar concentrations of ${ }^{14} \mathrm{C}$-labelled substrates has given interesting information about the relative capacity of the proximal convoluted tubule and the medullary and cortical thick ascending limb of the Henle loop to produce ${ }^{14} \mathrm{CO}_{2}$. Among the physiological substrates shown to be taken up in vivo by the rat kidney, glucose and lactate do not appear to be oxidized to a significant extent in the proximal convoluted tubule whereas glutamine and citrate and, to a much lesser extent, palmitate are readily oxidized by this nephron segment (Klein et al. 1981); in the thick ascending limb of Henle, glucose, lactate, glutamine and palmitate are oxidized at high rates and citrate at the lowest rate (Klein et al. 1981). Le Bouffant et al. (1984) also found that glucose is poorly oxidized in the proximal convoluted tubule, whereas it is oxidized at high rates, as is lactate, in the thick ascending limb of Henle, the distal convoluted tubule, and the cortical and the medullary collecting ducts. Le Bouffant et al. (1984) also observed that when glucose and lactate were available together lactate was the preferred fuel in the thick ascending limb of Henle, whereas the cortical collecting tubule oxidized glucose preferentially to lactate. An important role for long-chain free fatty acids as a source of energy has been demonstrated in rat renal cortical slices (Weidemann \& Krebs, 1969; Hohenegger et al. 1973) and outer medullary slices (Hohenegger et al. 1973). In contrast with the findings of Klein et al. (1981), a large proportion of the lactate taken up by proximal tubule suspensions from fed and starved rats has been shown to undergo complete oxidation (Guder \& Wieland, 1972; Janssens et al. 1980).

In microdissected proximal tubules, the best substrate (at a concentration of $2 \mathrm{mM}$ ) to maintain the cellular ATP content during incubation is glutamine followed by lactate and $\beta$-hydroxybutyrate but glucose is inefficient, whereas in microdissected cortical and medullary thick ascending limb of Henle, in distal convoluted tubule and in cortical and outer medullary collecting tubule, glucose and lactate are the best substrates followed by $\beta$-hydroxybutyrate and glutamine (Jung et al. 1989). Consistent with an important role for glucose in the provision of energy to distal, but not proximal, nephron segments is the observation that lactate accumulated from $5 \mathrm{mM}$-glucose only in microdissected rat thick ascending limb of Henle, distal convoluted tubule and cortical, outer and inner medullary collecting tubules, both in the absence and the presence of antimycin, an inhibitor of oxidative phosphorylation (Bagnasco et al. 1985).

\section{Adaptative changes in fuel selection by the rat kidney during starvation}

In the light of information available from arterio-venous difference measurements and on the metabolic segmentation of the nephron, one may attempt to provide a general picture of the selection of fuels by the various nephron segments of both fed and $72 \mathrm{~h}$-starved rats.

It is very likely that glucose, via anaerobic glycolysis, provides energy to all inner 
medullary structures irrespective of the nutritional state. Since glucose reabsorption is restricted to the proximal tubule (Frohnert et al. 1970), the glucose used is probably transported across the basolateral membrane of the cells of these inner medullary nephron segments by the facilitated diffusion glucose transporters GLUT 1 and GLUT 2 (Thorens et al. 1990; Chin et al. 1993). The very limited reserves of glycogen contained in these segments may represent a source of energy but only for very short periods, as shown during ischaemia (Needleman et al. 1968; Bastin et al. 1987). Although glucose and lactate, when present as the only substrates, seem to be the best energy providers to the thick ascending limb of Henle, the distal convoluted tubule and the cortical and outer medullary collecting tubule in the rat, it is conceivable, but not proven, that ketone bodies and perhaps also free fatty acids are the predominant fuels of these nephron segments, especially during starvation, because these substrates are known to reduce both glucose and lactate removal and oxidation by inhibiting pyruvate dehydrogenase (EC 1.2.4.1; Guder \& Wieland, 1972; Guder \& Schmidt, 1976). It should be mentioned that the basolateral membrane of the thick ascending limb of Henle is the only nephron segment containing the insulin-stimulated glucose transporter GLUT 4 (Chin et al. 1993). To our knowledge, the existence and the characteristics of apical and basolateral lactate transporters in these distal nephron segments in the rat remain to be established.

Although the transport of long-chain free fatty acids by the isolated perfused rat kidney is saturable (Trimble, 1982) and, therefore, possibly carrier-mediated (Trimble, 1989), the existence of such a carrier has not been demonstrated so far. It should be mentioned here that the kinetic characteristics of this transport do not change in perfused kidneys isolated from starved rats (Trimble, 1980). It is also noteworthy that no alteration in the activity of fatty acid-binding protein, present in the kidney and considered to play a role in the control of intracellular fatty acid metabolism, has not been reported during starvation (Paulussen et al. 1986).

Using rat renal cortical slices, Weidemann \& Krebs (1969) have demonstrated that ketone bodies inhibit the oxidation of free fatty acids; therefore, it is conceivable that during starvation ketone bodies inhibit fatty acid oxidation in the nephron segments present in the cortex, i.e. the proximal tubule, the distal convoluted tubule, the cortical thick ascending limb of Henle and the cortical collecting duct, which contain $\beta$-oxidation and citric acid cycle enzymes. The increased availability and uptake of fatty acids, leading to their increased conversion into triacylglycerols in the rat proximal tubule (Wirthensohn \& Guder, 1980), probably explains, at least in part, the augmented accumulation of triacylglycerols observed in the cortex of starved rats (Hohenegger \& Schuh, 1980; Wirthensohn et al. 1980). Whether the latter process contributes to reduced utilization of free fatty acids as fuels of respiration in the proximal tubule of starved rats is unknown.

The available evidence suggests that the proximal tubule reabsorbs all the glucose filtered through the glomerulus without any significant metabolism in the cells of the proximal tubule. Reabsorption of glucose in the proximal tubule occurs via the coupling of $\mathrm{Na}^{+}-$glucose cotransporters across the apical membrane (Dominguez et al. 1992) and of two facilitated diffusive glucose transporters, GLUT 1 and GLUT 2, which are localized in the basolateral membrane of proximal convoluted and straight tubules respectively (Thorens et al. 1990; Dominguez et al. 1992; Chin et al. 1993). It is probable that, in vivo, the proximal tubule also contributes to the basolateral efflux of the glucose synthesized by gluconeogenesis which has been shown to occur in various experimental 
preparations of the rat kidney cortex from lactate (Krebs et al. 1963; Weidemann \& Krebs, 1969; Guder \& Wieland, 1972; Janssens et al. 1980), glutamine (Watford et al. 1980), citrate (Kurokawa \& Rasmussen, 1973) and glycerol (Krebs et al. 1963; Guder et al. 1971). This glucose production probably masks, at the whole-organ level in vivo, the concurrent utilization of glucose by the distal segments of the nephron. Several authors have demonstrated that glucose can be metabolized by various preparations of the rat kidney (Underwood \& Newsholme, 1967; Weidemann \& Krebs, 1969; Hems \& Gaja, 1972; Ross et al. 1973; Anaizi \& Cohen, 1991). Although Elhamri et al. (1993) could not demonstrate a statistically significant change in renal glucose handling during starvation, there was a tendency for glucose removal to decrease in their study. This may be due to (1) a decrease in glucose utilization in distal segments of the nephron resulting from an intrinsic decrease in the ability to metabolize and oxidize glucose (Underwood \& Newsholme, 1967; Weidemann \& Krebs, 1969; Hems \& Gaja, 1972) and/or the increased availability and metabolism of ketone bodies and fatty acids (Underwood \& Newsholme, 1967; Weidemann \& Krebs, 1969) and (2) a starvation-induced stimulation of gluconeogenesis from lactate (Krebs et al. 1963, 1965, 1966; Janssens et al. 1980), glutamine (Iynedjian \& Peters, 1974; Bennett et al. 1975), and glycerol (Krebs et al. 1963; Underwood \& Newsholme, 1967). In the proximal tubule, the increased conversion of lactate into glucose at the expense of lactate oxidation during starvation may result from the sparing effect of fatty acids and ketone bodies (Krebs et al. 1965, 1966) and from the stimulation of pyruvate carboxylase by an elevated cellular acetyl-CoA level (Krebs et al. 1965). Increased transcription of the phosphoenolpyruvate carboxykinase gene known to occur in the kidney of starved rats (Meisner et al. 1985) and leading to the increased synthesis (Iynedjian et al. 1975) and activity of renal phosphoenolpyruvate carboxykinase (Iynedjian \& Peters, 1974; Bennett et al. 1975; Iynedjian et al. 1975), and to the increased levels of the corresponding mRNA (Pollock, 1989) also shown in acidosis (Iynedjian \& Hanson, 1977), represents another important mechanism whereby glucose synthesis not only from lactate but also from glutamine and perhaps from citrate is increased in the proximal tubule of starved rats. Burch et al. $(1978 b)$ have also demonstrated increased activity of phosphoenolpyruvate carboxykinase, fructose-1,6-bisphosphatase and glucose-6-phosphatase in the rat proximal tubule during starvation.

Given that glycerokinase, the enzyme initiating glycerol metabolism and forming 3-glycerophosphate, has a significant activity exclusively in the rat proximal tubule (Burch et al. 1982), the glycerol taken up across both the basolateral and apical membranes of the proximal tubular cells (Elhamri et al. 1993) can be either incorporated into triacylglycerols whose synthesis occurs in these cells (Wirthensohn \& Guder, 1980) or converted into glucose or $\mathrm{CO}_{2}$ (Krebs et al. 1963; Underwood \& Newsholme, 1967). Although the supply of glycerol to the kidney did not change during starvation, the significant increase in glycerol utilization observed across the basolateral membrane of the proximal tubule (Elhamri et al. 1993) does not necessarily mean that glycerol provided more energy (if any) to the proximal tubule because the renal cortex of starved rats stores more triacylglycerols (Hohenegger \& Schuh, 1980; Wirthensohn et al. 1980) and probably forms more glucose from glycerol as a result of the increased activity of fructose bisphosphatase and glucose-6-phosphatase (Burch et al. 1978b). The increase in glycerol-3-phosphate dehydrogenase ( $E C$ 1.1.1.8) activity observed by Robinson \& Newsholme (1969) in the kidney of starved rats may also be part of the mechanism 
responsible for the increased renal utilization of glycerol observed in vivo (Elhamri et al. 1993).

The observation that citrate was taken up across both the apical and basolateral membranes of renal cells (Elhamri et al. 1993) is consistent with the existence of tricarboxylate carriers at both poles of the renal cells (Windus et al. 1986; Burckhardt \& Ullrich, 1989). Since virtually all the filtered citrate is reabsorbed in the proximal tubule (Simpson, 1983), and since reabsorption provided half the citrate metabolized by the kidney (Elhamri et al. 1993), one may conclude that, in both the fed and starved state, at least half the citrate utilization occurs in the proximal tubule. It is likely that most of the basolateral uptake of citrate also occurs in the proximal tubule, but, since citrate has been shown to undergo some oxidation in microdissected thick ascending limb of Henle (Klein et al. 1981), one cannot rule out the possibility that some citrate was transported across the basolateral membrane of this nephron segment and then oxidized. In rat renal cortical slices, citrate is converted at least in part into $\mathrm{CO}_{2}$ (Adler \& Preuss, 1972); thus, citrate represents a source of energy for the proximal tubule even if it is substantially converted into glucose, because the latter process yields energy. It is unknown whether, as has been demonstrated in isolated rat cortical tubules incubated in acidic $\mathrm{pH}$ (Kurokawa \& Rasmussen, 1973), the synthesis of glucose from citrate is augmented in the proximal tubule of starved rats at the expense of complete oxidation of citrate as a result of stimulation of the key enzymes of gluconeogenesis located in the pathway between oxaloacetate and glucose. Whether the increase in citrate oxidation observed in rat renal cortical slices of chronically acidotic rats (Adler \& Preuss, 1972) also holds true in the renal cortex of starved rats and whether this increase in citrate oxidation is due to the partial oxidation associated with glucose synthesis or to an increase in complete oxidation of citrate remains to be studied.

In the fed state, the rat kidney takes up glutamine only from the lumen fluid and an efflux of glutamine is observed at the basolateral pole of renal cells (Elhamri et al. 1993). Since the filtered glutamine is almost quantitatively reabsorbed in the proximal tubule (Silbernagl, 1980), this means that most, if not all, the glutamine utilization occurs in the cells of this nephron segment which contains not only significant activities of glutaminase and glutamate dehydrogenase (EC 1.4.1.2; Curthoys \& Lowry, 1973; Wright \& Knepper, 1990a,b) but also the enzymes of the tricarboxylic acid cycle and of gluconeogenesis (see pp. 201-202). Several authors have demonstrated that glutamine may be converted into glucose and $\mathrm{CO}_{2}$ by rat proximal tubules or slices in vitro (Kamm \& Strope, 1972; Baverel \& Lund, 1979; Watford et al. 1980; Baverel et al. 1984). The net provision of energy during glutamine metabolism results from both complete oxidation of its carbon skeleton and, to a lesser extent, gluconeogenesis (Halperin et al. 1982). Therefore, irrespective of the relative importance of complete oxidation and glucose synthesis from glutamine, this amino acid appears to be an energy supplier to the proximal tubule of fed rats.

Starvation was found to increase the uptake of glutamine by the rat kidney in vivo by conversion of the net basolateral efflux of glutamine into a net influx (Elhamri et al. 1993); this effect, which cannot result from a change in the kinetic properties of the basolateral glutamine transporter (Foreman et al. 1983), was accompanied by a stimulation of the production, excretion and venous release of $\mathrm{NH}_{4}{ }^{+}$without any concomitant increase in glutamine release; this indicates that flux through glutaminase and glutamate dehydrogenase was augmented (Elhamri et al. 1993). Although, in the 
latter study, no systemic metabolic acidosis was observed after $72 \mathrm{~h}$ of starvation, such a stimulation of renal ammoniagenesis from glutamine is probably indicative of an adaptative response of the kidney to the initial metabolic acidosis (fully compensated after $72 \mathrm{~h}$ of starvation) due to the increased production of acetoacetic and $\beta$-hydroxybutyric acids by the liver. The metabolic acidosis-induced stimulation of glutamine metabolism, which is due to (1) a stimulation of glutaminase activity (Curthoys \& Lowry, 1973; Wright \& Knepper, 1990b) resulting from increased synthesis of this enzyme via the stabilization of glutaminase mRNA (Hwang \& Curthoys, 1991) and (2) the stimulation of the activity and of the flux through glutamate dehydrogenase (Schoolwerth et al. 1978; Wright \& Knepper, 1990a), together with the associated enhancement of $\mathrm{NH}_{4}{ }^{+}$production from glutamine, is restricted to the $\mathrm{S} 1$ and $\mathrm{S} 2$ segments of the proximal tubule (Good \& Burg, 1984; Nonoguchi et al. 1986). Other factors capable of stimulating glutamine metabolism are a fall in intramitochondrial $\mathrm{pH}$ (Schoolwerth \& Gesek, 1990), which leads to a stimulation of oxoglutarate dehydrogenase (EC 1.2.4.2) activity (Lowry \& Ross, 1980), and the stimulation of phosphoenolpyruvate carboxykinase already mentioned.

Under acidotic conditions, flux through glutamine synthetase has been found to be decreased in the rat kidney in vivo (Damian \& Pitts, 1970) and glutamine synthesis from glutamate is also decreased in the isolated perfused rat kidney (Hems, 1972). Together with the stimulation of unidirectional glutamine utilization, this may contribute to the increased net glutamine utilization observed in the kidney of starved rats (Elhamri et al. 1993). Inhibition of glutamine utilization and, therefore, of glutamine oxidation by $\beta$-hydroxybutyrate in the fed state observed by Goldstein et al. $(1980,1982)$ is probably reduced in the starved state because, under ketotic conditions, the rat kidney does not appear to be sensitive to the inhibitory effects of ketone bodies. Since experimental evidence obtained in the isolated perfused rat kidney suggests that the extra glutamine taken up in acidosis is accounted for by the extra glucose formed (Hems, 1972), it is likely that the 3-fold stimulation of glutamine utilization observed in vivo in the kidney of starved rats (Elhamri et al. 1993) was accompanied by an enhanced contribution of glutamine to the provision of energy in the proximal tubule. Despite the presence of the enzymic machinery for glutamine metabolism and the evidence for some glutamine oxidation (Klein et al. 1981; Jung et al. 1989), it remains unknown whether or not significant amounts of glutamine are taken up across the basolateral membrane and oxidized in other nephron segments in vivo.

Since at low (physiological) concentrations, filtered ketone bodies are reabsorbed mainly in the proximal tubule (Ferrier et al. 1992), and since ketone bodies are also taken up across the basolateral membrane of proximal tubular cells by a diffusion mechanism (Ullrich \& Papavassiliou, 1986), it is very likely that a large proportion of the metabolism of the ketone bodies taken up by the rat kidney in vivo (Elhamri et al. 1993) occurs in the proximal tubule both in fed and starved rats. The preferential utilization of acetoacetate in the fed state may be due to its higher blood concentration (Elhamri et al. 1993). It should be noted that the capacity or affinity of the apical transporter of ketone bodies did not change in brush-border-membrane vesicles prepared from starved rats (Barac-Nieto, 1986). By contrast, although the circulating concentration of $\beta$-hydroxybutyrate was much greater than that of acetoacetate, the rates of utilization of these two compounds were similar during starvation and the basolateral efflux of $\beta$-hydroxybutyrate observed in fed rats persisted and even increased in starved animals (Elhamri et al. 1993). This may 
reflect a limitation of the metabolism of $\beta$-hydroxybutyrate by $\beta$-hydroxybutyrate dehydrogenase ( $E C$ 1.1.1.30) secondary to a reduction of the activity of this enzyme (Kante et al. 1990) and to the shift to a more reduced state of the NAD-NADH couple during starvation as reflected by the blood $\beta$-hydroxybutyrate:acetoacetate value which increased in starved animals when compared with fed rats (Elhamri et al. 1993, see also Table 1).

Micropuncture experiments have shown that ketone bodies are not reabsorbed along the distal convoluted tubule or the collecting duct but a reabsorption of ketone bodies in the thick ascending limb of Henle when blood ketone body concentration is elevated cannot be excluded (Ferrier et al. 1992). Whether monocarboxylate carriers, whose existence has been demonstrated in the apical membrane of the proximal tubule (Garcia et al. 1980; Jörgensen \& Sheikh, 1985), exist and transport ketone bodies across the apical membrane of the thick ascending limb of Henle in the rat remains unknown. Similarly, the possible existence of basolateral transporters of ketone bodies in certain distal nephron segments in the rat has not been demonstrated so far. However, because of the high rate of ketone-body utilization during starvation, the fate of these compounds, which seems to be only oxidation, and the fact that their oxidation would account for most of the $\mathrm{O}_{2}$ consumed by the rat kidney in vivo (see Table 1), it is likely that these compounds represent the main fuels of all the nephron segments equipped with the enzymes of ketone-body degradation.

\section{CONCLUSION}

At the whole-organ level, lactate and perhaps glucose seem to be the main fuels of the kidney of fed rats, but all the other substrates taken up in significant amounts (ketone bodies, free fatty acids, citrate, glutamine and glycerol) probably also contribute to the provision of energy; during starvation, ketone bodies and perhaps free fatty acids and, to a lesser extent, glucose seem to be the preferred fuels of the kidney, whereas the stimulation of gluconeogenesis known to occur in this nutritional situation probably limits the contribution of lactate and glycerol and augments the contribution of glutamine and perhaps citrate to the synthesis of ATP.

At the nephron segment level, glucose is not a fuel in the proximal tubule but probably represents the only significant source of energy of all the nephron segments located in the inner medulla. The proximal tubule has the capacity to oxidize all the other substrates taken up. It is conceivable, therefore, that they all supply energy to the proximal tubule in fed rats but, given the quantitative importance of renal lactate uptake in vivo, it is likely that lactate represents the main fuel of this segment. In starved rats, the proximal tubule probably relies mainly on ketone bodies for its energetic needs; the free fatty acids taken up by this segment seem to undergo, at least in part, esterification and storage and the extent to which they are oxidized is uncertain. It is also possible that the glycerol and perhaps the citrate taken up by the proximal tubule of starved rats are diverted away from oxidation. The other nephron segments (cortical and outer medullary thick ascending limb of Henle, the distal convoluted tubule and the cortical and outer medullary collecting duct) have the capacity to oxidize significant amounts of glucose, lactate, ketone bodies and free fatty acids; it is likely that in fed rats they use, to variable extents, a mixture of these substrates as energy sources. In starved rats there is little doubt that these nephron segments shift their preference to ketone bodies and fatty acids as respiratory fuels. 
Thus, the complexity of the structural, functional and biochemical organization of the kidney makes the conclusions uncertain and much remains to be learned about the relative quantitative importance of (1) the fuels utilized by the whole kidney under different nutritional situations and (2) the successive nephron segments involved in energy production. Only some of the mechanisms by which the kidney selects its fuels in a given nutritional state and under changing situations are known; in particular, as recognized by Guder \& Morel (1992), relatively little is known about the regulation of renal intermediary metabolism by hormones.

Finally, it should be emphasized that the conclusions drawn from results obtained in the rat kidney do not necessarily apply to the kidney of other species. For example, the proximal tubules of the rabbit and guinea-pig kidney substantially oxidize glucose (Gullans et al. 1984; Chauvin et al. 1994; Michoudet et al. 1994), and the human kidney in vivo, like the rat kidney, takes up large amounts of $\beta$-hydroxybutyrate during starvation but, in contrast to the rat kidney, releases large amounts of acetoacetate (Owen et al. 1969).

\section{REFERENCES}

Adler, S. \& Preuss, H. G. (1972). Interrelationships between citrate metabolism, ammoniagenesis, and gluconeogenesis in renal cortex in vitro. Journal of Laboratory and Clinical Medicine 79, 505-515.

Anaizi, N. H. \& Cohen, J. J. (1991). Kinetics of glucose decarboxylation in the substrate-limited isolated perfused kidney. Renal Physiology and Biochemistry 14, 81-91.

Bagnasco, S., Good, D., Balaban, R. \& Burg, M. (1985). Lactate production in isolated segments of the rat nephron. American Journal of Physiology 248, F522-F526.

Barac-Nieto, M. (1986). Renal reabsorption and utilization of hydroxybutyrate and acetoacetate in starved rats. American Journal of Physiology 251, F257-F265.

Bartlett, S., Espinal, J., Janssens, P. \& Ross, B. D. (1984). The influence of renal function on lactate and glucose metabolism. Biochemical Journal 219, 73-78.

Bastin, J., Cambon, N., Thompson, M., Lowry, O. H. \& Burch, H. (1987). Change in energy reserves in different segments of the nephron during brief ischemia. Kidney International 31, 1239-1247.

Baverel, G. \& Lund, P. (1979). A role for bicarbonate in the regulation of mammalian glutamine metabolism. Biochemical Journal 184, 599-606.

Baverel, G., Michoudet, C. \& Martin, G. (1984). Role of fatty acids in simultaneous regulation of flux through glutaminase and glutamine synthetase in rat kidney cortex. In Glutamine Metabolism in Mammalian Tissues, pp. 187-202 [D. Häussinger and H. Sies, editors]. Berlin: Springer Verlag.

Bennett, F. I., Alexander, J. E., Roobol, A. \& Alleyne, G. A. O. (1975). Effect of starvation on renal metabolism in the rat. Kidney International 7, 380-384.

Bowman, R. H. (1970). Gluconeogenesis in the isolated perfused rat kidney. Journal of Biological Chemistry 245, 1604-1612.

Burch, H. B., Bross, T. E., Brooks, C. A., Cole, B. R. \& Lowry, O. H. (1984). The distribution of six enzymes of oxidative metabolism along the rat nephron. Journal of Histochemistry and Cytochemistry 32, 731-736.

Burch, H. B., Choi, S., McCarthy, W. Z., Wong, P. Y. \& Lowry, O. H. (1978a). The location of glutamine synthetase within the rat and the rabbit nephron. Biochemical and Biophysical Research Communications 82, 498-505.

Burch, H. B., Hays, A. E., McCreary, M. D., Cole, B. R., Chi, M. M. Y., Dence, C. N. \& Lowry, O. H. (1982). Relationships in different parts of the nephron between enzymes of glycerol metabolism and the metabolite changes which result from large glycerol loads. Journal of Biological Chemistry 257, 3676-3679.

Burch, H. B., Lowry, O. H., Perry, S. G., Fan, L. \& Fagioli, S. (1974). Effect of age on pyruvate kinase and lactate dehydrogenase distribution in rat kidney. American Journal of Physiology 226, 1227-1231.

Burch, H. B., Narins, R. G., Chu, C., Fagioli, S., Choi, S., McCarthy, W. \& Lowry, O. H. (1978b). Distribution along the rat nephron of three enzymes of gluconeogenesis in acidosis and starvation. American Journal of Physiology 235, F246-F253.

Burckardt, G. \& Ullrich, K. J. (1989). Organic anion transport across the contraluminal membrane. Dependence on sodium. Kidney International 36, 370-377. 
Chauvin, M. F., Mégnin-Chanet, F., Martin, G., Lhoste, J. M. \& Baverel, G. (1994). The rabbit kidney tubule utilizes glucose for glutamine synthesis. A ${ }^{13} \mathrm{C}$ NMR study. Journal of Biological Chemistry 269, $26025-26033$.

Chin, E., Zhou, J. \& Bondy, C. (1993). Anatomical and developmental patterns of facilitative glucose transporter gene expression in the rat kidney. Journal of Clinical Investigation 91, 1810-1815.

Churchill, P. C., Belloni, F. L. \& Churchill, M. C. (1973). Net glucose release in the rat. American Journal of Physiology 225, 528-531.

Cohen, J. J. \& Barac-Nieto, M. (1973). Renal metabolism of substrates in relation to renal function. In Handbook of Physiology. Section 8: Renal Physiology, pp. 909-1011 [J. Orloff and R. W. Berliner, editors]. Washington, D.C.: American Physiological Society.

Cohen, J. J., Kook, Y. J. \& Little, J. R. (1977). Substrate-limited function and metabolism of the isolated perfused rat kidney: Effects of lactate and glucose. Journal of Physiology 266, 103-121.

Curthoys, N. P. \& Lowry, O. H. (1973). The distribution of glutaminase isoenzymes in the various structures of the nephron in normal, acidotic and alkalotic rat kidney. Journal of Biological Chemistry 248, 162-168.

Damian, A. C. \& Pitts, R. F. (1970). Rates of glutaminase I and glutamine synthetase reactions in rat kidney in vivo. American Journal of Physiology 218, 1249-1255.

Dominguez, J. H., Camp, C., Maianu, L. \& Garvey, W. T. (1992). Glucose transporters of rat proximal tubule: differential expression and subcellular distribution. American Journal of Physiology 262, F807F812.

Elhamri, M., Martin, M., Ferrier, B. \& Baverel, G. (1993). Substrate uptake and utilization by the kidney of fed and starved rats in vivo. Renal Physiology and Biochemistry 16, 311-324.

Ferrier, B., Martin, M., Janbon, B. \& Baverel, G. (1992). Transport of $\beta$-hydroxybutyrate and acetoacetate along the rat nephron: a micropuncture study. American Journal of Physiology 262, F762-F769.

Foreman, J. W., Reynolds, R. A., Ginkinger, K. \& Segal, S. (1983). Effect of acidosis on glutamine transport by isolated renal brush-border and basolateral-membrane vesicles. Biochemical Journal 212, 713-720.

Frohnert, P. P., Hohman, B., Zwiebel, R. \& Baumann, K. (1970). Free flow micropuncture studies of glucose transport in the rat nephron. Pfïgers Archiv 315, 66-85.

Garcia, M. L., Benavides, J. \& Valdivieso, F. (1980). Ketone body transport in renal brush-border membrane vesicles. Biochimica et Biophysica Acta 600, 922-930.

Goldstein, L. (1987). Renal substrate utilization in normal and acidotic rats. American Journal of Physiology 253, F351-F357.

Goldstein, L., Boylan, J. M. \& Schröck, H. (1980). Adaptation of renal ammonia production in the diabetic ketoacidotic rat. Kidney International 17, 57-65.

Goldstein, L., Solomon, R. J., Perlman, D. F., McLaughlin, P. M. \& Taylor, M. A. (1982). Ketone body effects on glutamine metabolism in isolated kidneys and mitochondria. American Journal of Physiology 243, F181-F187.

Good, D. \& Burg, M. (1984). Ammonia production by individual segments of the rat nephron. Journal of Clinical Investigation 73, 602-610.

Guder, W. G. \& Morel, F. (1992). Biochemical characterization of individual nephron segments. In Handbook of Physiology. Section 8: Renal Physiology, vol. 2, pp. 2119-2164 [E. E. Windhager, editor]. Oxford: Oxford University Press.

Guder, W. G. \& Ross, B. D. (1984). Enzyme distribution along the nephron. Kidney International 26, 101-111.

Guder, W. G. \& Schmidt, U. (1976). Substrate and oxygen dependence of renal metabolism. Kidney International 10, S32-S38.

Guder, W. G., Wagner, S. \& Wirthensohn, G. (1986). Metabolic fuels along the nephron: Pathways and intracellular mechanisms of interaction. Kidney International 29, 41-45.

Guder, W. G. \& Wieland, O. H. (1972). Metabolism of isolated kidney tubules. Additive effects of parathyroid hormone and free fatty acids on renal gluconeogenesis. European Journal of Biochemistry 31, 69-79.

Guder, W. G., Wiesner, W., Stukowski, B. \& Wieland, O. (1971). Metabolism of isolated kidney tubules. Oxygen consumption, gluconeogenesis and the effect of cyclic nucleotides in tubules from starved rats. Hoppe-Seyler's Zeitschrift für physiologische Chemie 352, 1319-1328.

Gullans, S. R., Harris, S. I. \& Mandel, L. J. (1984). Glucose-dependent respiration in suspensions of rabbit cortical tubules. Journal of Membrane Biology 78, 257-262.

Halperin, M., Jungas, R. L., Pichette, C. \& Goldstein, M. (1982). A quantitative analysis of renal ammoniagenesis and energy balance: a theoretical approach. Canadian Journal of Physiology and Pharmacology 60, 1431-1435. 
Hems, D. A. (1972). Metabolism of glutamine and glutamic acid by isolated perfused kidneys of normal and acidotic rats. Biochemical Journal 130, 671-680.

Hems, D. A. \& Gaja, G. (1972). Carbohydrate metabolism in the isolated perfused rat kidney. Biochemical Journal 128, 421-426.

Hohenegger, M. \& Schuh, H. (1980). Uptake and fatty acid synthesis by the rat kidney. International Journal of Biochemistry 12, 169-172.

Hohenegger, M., Wittmann, G. \& Dalheim, H. (1973). Oxidation of fatty acids by different zones of the rat kidney. Pfliugers Archiv 341, 105-112.

Hus-Citharel, A. \& Morel, F. (1986). Coupling of metabolic $\mathrm{CO}_{2}$ production to ion transport in isolated rat thick ascending limbs and collecting tubules. Pflügers Archiv 407, 421-427.

Hwang, J. J. \& Curthoys, N. P. (1991). Effect of acute alterations in acid-base balance on rat renal glutaminase and phosphoenolpyruvate carboxykinase gene expression. Journal of Biological Chemistry 266, 9392-9396.

Iynedjian, P. B., Ballard, F. J. \& Hanson, R. W. (1975). The regulation of phosphoenolpyruvate carboxykinase (GTP) synthesis in rat kidney cortex. The role of acid-base balance and glucocorticoids. Journal of Biological Chemistry 250, 5596-5603.

Iynedjian, P. B. \& Hanson, R. W. (1977). Messenger RNA for renal phosphoenolpyruvate carboxykinase (GTP). Joumal of Biological Chemistry 252, 8398-8403.

Iynedjian, P. B. \& Peters, G. (1974). Phosphoenolpyruvate carboxykinase and gluconeogenesis in renal cortex of starved rats. American Journal of Physiology 226, 1281-1285.

Janssens, P., Hems, R. \& Ross, B. (1980). The metabolic fate of lactate in renal cortical tubules. Biochemical Journal 190, 27-37.

Jörgensen, K. E. \& Sheikh, M. I. (1985). Mechanisms of uptake of ketone bodies by luminal-membrane vesicles. Biochimica et Biophysica Acta 814, 23-34.

Jung, K. Y., Uchida, S. \& Endou, H. (1989). Nephrotoxicity assessment by measuring cellular ATP content. I. Substrate specificities in the maintenance of ATP content in isolated rat nephron segments. Toxicology and Applied Pharmacology 100, 369-382.

Kamm, D. E. \& Strope, G. L. (1972). The effects of acidosis and alkalosis on the metabolism of glutamine and glutamate in renal cortex slices. Journal of Clinical Investigation 51, 1251-1263.

Kante, A., Malki, M. C., Coquard, C. \& Latruffe, N. (1990). Metabolic control of the expression of mitochondrial D- $\beta$-hydroxybutyrate dehydrogenase, a ketone body converting enzyme. Biochimica et Biophysica Acta 1033, 291-297.

Kida, K., Nakajo, S., Kamiya, F., Toyama, Y., Nishio, T. \& Nakagawa, H. (1978). Renal net glucose release in vivo and its contribution to blood glucose in rats. Journal of Clinical Investigation 62, 721-726.

Klein, K. L., Wang, M. S., Torikai, S., Davidson, W. D. \& Kurokawa, K. (1981). Substrate oxidation by isolated single nephron segments of the rat. Kidney International 20, 29-35.

Krebs, H. A., Bennett, D. A. H., de Gasquet, P., Gascoyne, T. \& Yoshida, T. (1963). Renal gluconeogenesis. The effect of diet on the gluconeogenic capacity of rat-kidney-cortex slices. Biochemical Journal 86, 22-27.

Krebs, H. A., Hems, R., Weidemann, M. J. \& Speake, R. N. (1966). The fate of isotopic carbon in kidney cortex synthesizing glucose from lactate. Biochemical Journal 101, 242-248.

Krebs, H. A., Speake, R. N. \& Hems, R. (1965). Acceleration of renal gluconeogenesis by ketone bodies and fatty acids. Biochemical Journal 94, 712-720.

Kriz, W. \& Bankir, L. (1988). A standard nomenclature for structures of the kidney. Kidney International 33, $1-7$.

Kurokawa, K. K., Nagami, G. \& Yamaguchi, D. T. (1985). Transport and substrate metabolism of the kidney. In Renal Biochemistry, pp. 176-223 [R. K. H. Kinne, editor]. Amsterdam: Elsevier Science Publishers B.V.

Kurokawa, K. \& Rasmussen, H. (1973). Ionic control of renal gluconeogenesis. III. The effects of changes in $\mathrm{pH}, \mathrm{pCO} 2$, and bicarbonate concentration. Biochimica et Biophysica Acta 313, 42-58.

Le Bouffant, F., Hus-Citharel, A. \& Morel, F. (1984). Metabolic $\mathrm{CO}_{2}$ production by isolated single pieces of rat distal nephron. Pflügers Archiv 401, 346-353.

Le Hir, M. \& Dubach, U. C. (1982a). Activities of enzymes of the tricarboxylic acid cycle in segments of the rat nephron. Pflügers Archiv 395, 239-245.

Le Hir, M. \& Dubach, U. C. (1982b). Peroxisomal and mitochondrial beta-oxidation in the rat kidney: Distribution of fatty-acyl-coenzyme A oxidase and 3-hydroxyacyl-coenzyme A dehydrogenase activities along the nephron. Journal of Histochemistry and Cytochemistry 30, 441-444.

Leichtweiss, H. P., Lübbers, D. W., Weiss, C., Baumgärtl, H. \& Reschke, W. (1969). The oxygen supply of the rat kidney: Measurements of intrarenal $\mathrm{pO}_{2}$. Pfiugers Archiv 309, 328-349. 
Lemieux, G., Baverel, G., Vinay, P. \& Wadoux, P. (1976). Glutamine synthetase and glutamyltransferase in the kidney of man, dog and rat. American Journal of Physiology 231, 1068-1073.

Lowry, M. \& Ross, B. D. (1980). Activation of oxoglutarate dehydrogenase in the kidney in response to acute acidosis. Biochemical Journal 190, 771-780.

Meisner, H. M., Loose, D. S. \& Hanson, R. W. (1985). Effect of hormones on transcription of the gene for cytosolic phosphoenolpyruvate carboxykinase (GTP) in rat kidney. Biochemistry 24, 421-425.

Michoudet, C., Chauvin, M. F. \& Baverel, G. (1994). Glutamine synthesis from glucose and ammonium chloride by guinea-pig kidney tubules. Biochemical Journal 297, 69-74.

Needleman, P., Passonneau, J. \& Lowry, O. H. (1968). Distribution of glucose and related metabolites in rat kidney. American Journal of Physiology 215, 655-659.

Nishiitsuji, J. M., Ross, B. D. \& Krebs, H. A. (1967). Metabolic activities of the isolated perfused rat kidney. Biochemical Journal 103, 852-862.

Nonoguchi, H., Takehara, Y. \& Endou, H. (1986). Intra- and inter-nephron heterogeneity of ammoniagenesis in rats: effects of chronic metabolic acidosis and potassium depletion. Pflügers Archiv 407, 245-251.

Owen, O. E., Felig, P., Morgan, A. P., Wahren, J. \& Cahill, G. F. (1969). Liver and kidney metabolism during prolonged starvation. Journal of Clinical Investigation 48, 574-583.

Paulussen, R. J. A., Jansen, G. P. M. \& Veerkamp, J. H. (1986). Fatty acid-binding capacity of cytosolic proteins of various rat tissues: effect of postnatal development, starvation, sex, clofibrate feeding and light cycle. Biochimica et Biophysica Acta 877, 342-349.

Pfaller, W. \& Rittinger, M. (1980). Quantitative morphology of the rat kidney. International Journal of Biochemistry 12, 17-22.

Pollock, A. S. (1989). Induction of renal phosphoenolpyruvate carboxykinase mRNA: suppressive effect of glucose. American Journal of Physiology 257, F145-F151.

Richterich, R. W. \& Goldstein, L. (1958). Distribution of glutamine metabolizing enzymes and production of urinary ammonia in the mammalian kidney. American Journal of Physiology 195, 316-320.

Robinson, A. M. \& Williamson, D. H. (1980). Physiological roles of ketone bodies as substrates and signals in mammalian tissues. Physiological Reviews 60, 143-187.

Robinson, J. \& Newsholme, E. A. (1969). The effects of dietary conditions and glycerol concentration on glycerol uptake by rat liver and kidney-cortex slices. Biochemical Journal 112, 449-453.

Ross, B. D., Epstein, F. \& Leaf, A. (1973). Sodium reabsorption in the perfused rat kidney. American Journal of Physiology 225, 1165-1171.

Ross, B. D. \& Guder, W. G. (1982). Heterogeneity and compartmentation in the kidney. In Metabolic Compartmentation, pp. 363-409 [H. Sies, editor]. London: Academic Press.

Salto, R., Oliver, J., del Mar Sola, M. \& Vargas, A. M. (1991). Distribution of pyruvate carboxylase along the rat nephron: An immunological and enzymatic study. Kidney International 39, 1162-1167.

Silbernagl, S. (1980). Tubular reabsorption of L-glutamine studied by free-flow micropuncture and microperfusion of rat kidney. International Journal of Biochemistry 12, 9-16.

Simpson, D. (1983). Citrate excretion: a window on renal metabolism. American Journal of Physiology 244, F223-F234.

Schmidt, U. \& Dubach, U. C. (1976). Acute renal failure in the folate-treated rat: Early metabolic changes in various structures of the nephron. Kidney International 10, S39-S45.

Schmidt, U., Marosvari, I. \& Dubach, U. C. (1975). Renal metabolism of glucose: anatomical sites of hexokinase activity in the rat nephron. FEBS Letters 53, 26-28.

Schoolwerth, A. C. \& Gesek, F. A. (1990). Intramitochondrial pH and ammonium production in rat and dog kidney cortex. Mineral and Electrolyte Metabolism 16, 264-269.

Schoolwerth, A. C., Nazar, B. L. \& LaNoue, K. F. (1978). Glutamate dehydrogenase activation and ammonia formation by rat kidney mitochondria. Journal of Biological Chemistry 253, 6177-6183.

Squires, E. J., Hall, D. E. \& Brosnan, J. T. (1976). Arteriovenous differences for amino acids and lactate across kidneys of normal and acidotic rats. Biochemical Journal 160, 125-128.

Tannenbaum, J., Purkerson, M. L. \& Klahr, S. (1983). Effect of unilateral ureteral obstruction on metabolism of renal lipids in the rat. American Journal of Physiology 245, F254-F262.

Thorens, B., Lodish, H. F. \& Brown, D. (1990). Differential localization of two glucose transporter isoforms in rat kidney. American Journal of Physiology 259, C286-C294.

Trimble, M. E. (1980). Uptake and utilization of long chain and medium chain fatty acids by the perfused rat kidney. International Journal of Biochemistry 12, 173-176.

Trimble, M. E. (1982). Long chain fatty acid transport by the perfused rat kidney. Renal Physiology 5, 136-142. 
Trimble, M. E. (1989). Mediated transport of long-chain fatty acids by rat renal basolateral membranes. American Journal of Physiology 257, F539-F546.

Ullrich, K. J. \& Papavassiliou. F. (1986). Contraluminal transport of small aliphatic carboxylates in the proximal tubule of the rat kidney in situ. Pflügers Archiv 407, 488-492.

Underwood, A. H. \& Newsholme, E. A. (1967). Control of glycolysis and gluconeogenesis in rat kidney cortex slices. Biochemical Journal 104, 300-305.

Watford, M., Vinay, P., Lemieux, G. \& Gougoux, A. (1980). The regulation of glucose and of pyruvate formation from glutamine and citric-acid-cycle intermediates in the kidney cortex of rats, dogs, rabbits and guinea-pigs. Biochemical Journal 188, 741-748.

Weidemann, M. J. \& Krebs, H. A. (1969). The fuel of respiration of rat kidney cortex. Biochemical Journal $112,149-166$.

Weinstein, S. W. \& Szyjewick, J. (1976). Single nephron function and renal oxygen consumption during rapid volume expansion. American Journal of Physiology 231, 1166-1172.

Windus, D. W., Cohn, D. E. \& Heifets, M. (1986). Effect of fasting on citrate transport by brush border membrane of rat kidney. American Journal of Physiology 251, F678-F682.

Wirthensohn, G., Gerl, M. \& Guder, W. (1980). Triacylglycerol metabolism in kidney cortex and outer medulla. International Journal of Biochemistry 12, 157-161.

Wirthensohn, G. \& Guder, W. G. (1980). Triacylglycerol metabolism in isolated rat kidney cortex tubules. Biochemical Journal 186, 317-324.

Wirthensohn, G. \& Guder, W. G. (1986). Renal substrate metabolism. Physiological Reviews 66, 469-497.

Wright, P. A. \& Knepper, M. A. (1990a). Glutamate dehydrogenase activities in microdissected rat nephron segments: effects of acid-base loading. American Journal of Physiology 259, F53-F59.

Wright, P. A. \& Knepper, M. A. (1990b). Phosphate-dependent glutaminase activity in rat renal cortical and medullary tubule segments. American Journal of Physiology 259, F961-F970. 